\section{Premier Is First Hospital Group to Join Joint Commission IMS Project}

In early January, Premier Health Alliance Inc. became the first hospital group to become a "quality partner" in the Joint Commission on Accreditation of Healthcare Organizations' Indicator Measurement System (IMS). The IMS, which is intended to help hospitals improve patient care quality, is designed to be a reference database on hospital clinical performance.

Participation in IMS is voluntary in 1994 and 1995. When the Joint Commission makes it an integral part of the accreditation process in 1996 or 1997, reports containing hospital-specific indicator information will be available to the public, along with comparative national data.

A spokesperson for Premier said discussions had begun with officials from its 50-member tertiary not-forprofit hospitals, systems, and networks about voluntarily enrolling in the IMS project. The Joint Commission expects about half of Premier's members to participate.

The IMS this year will allow participating hospitals to measure and compare their performance using 10 obstetrical and performance indicators. In 1995 and 1996, indicators covering trauma care, oncology care, cardiovascular care, medication use, infection control, and other areas will be added.

FROM: AHA News January 10, 1994.

\section{Resurgence of Pertussis in United States}

From January 3, 1993, through December 4, 1993, 5,457 pertussis cases were reported to the CDC-an $83 \%$ increase over the number reported during the same period in 1992 ( 3004 cases) and the highest annual number of cases reported since 1967. Almost $44 \%$ of cases were infants ( $<1$ year), $20 \%$ were aged 1 to $4,11 \%$ were 5 to 9 years old, and $23 \%$ were over 10 years old. Sixty-one percent of cases had received fewer than three doses of diphtheria and tetanus toxoid and pertussis vaccine (DTP).

In addition to prevention through vaccination, control of pertussis and interruption of transmission requires prompt recognition of disease by healthcare providers and timely administration of effective antimicrobials (ie, erythromycin or trimethoprim-sulfamethoxazole) to persons with pertussis or their close contacts. Healthcare providers should suspect the diagnosis of pertussis in persons of all age groups who develop a cough lasting more than 7 days.

FROM: Centers for Disease Control and Prevention. Resurgence of pertussis. M M WR 1993;42:952-953.

\section{Classified Marketplace}

\section{FOR SALE}

END LATEX EXPOSURE

NONLATEX DISPOSABLE GLOVES: Tactile sensitivity, manual dexterity equal to or better than latex gloves. For a FREE sample call:

\author{
TRU-BLU SUPPLY \\ 800-968-5460 \\ FAX (501)968-5224
}

\section{SERVICES}

A FAX MACHINE IS AVAILABLE FOR YOUR CONVENIENCE. FAX YOUR CLASSIFIED AD TODAY for placement in the next issue of INFECTION CONTROL AND HOSPITAL EPIDEMIOLOGY Classified Marketplace (609) 853-5991.

\section{Infection Contr}

Provident Hospital of CoOK County, a teaching community public hospital, has a unique and challenging position for an Infection Control Practitioner to help implement the Infection Control Program. The candidate should have at least two years' recent experience in Infection Control in the following areas:

- Surveillance

- Reporting of communicable diseases

- Occupational Healch

- Inservice presentations

- Outbreak management

The candidate should be knowledgeable of JCAHO, IDPH, CDOH, CDC and OSHA Infection Control Guidelines.

B.S. degree is preferred from an accredited school of Nursing or Physician Assistants programs. Knowledge of microbiology, statistics and personal computers, ability to communicate effectively with a wide variety of individuals and to write accurate, concise reports.

The position reports to the Infection Control Manager. The Infection Control Department is under the jurisdiction of the Quality Services Department of PHCC.

We offer excellent salary and benefits. Please send resume to Carol Reliford, Human Resources, (3 12) 572 - 1415:

\section{Provident Hospital of Cook County 500 East 51 st Street EOE Chicago, Illinois 60615}



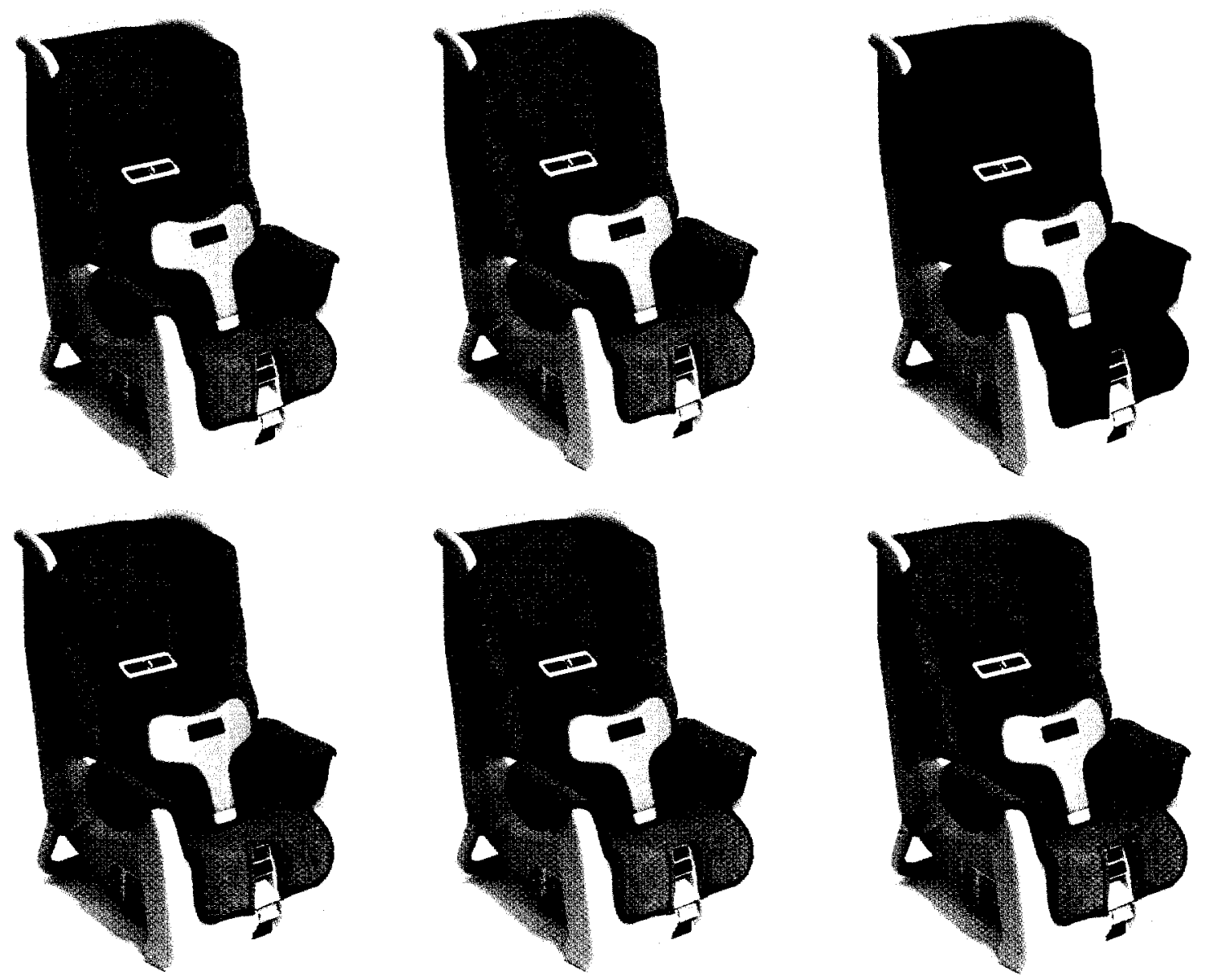

\section{If the blue one protected 4 times better, would you use it?}

When a risk arises, it's not a question of if you should protect yourself but how to best protect yourself.

With costly central venous catheter-related infections occurring at a rate of $3 \%$ to $12 \%$, and an associated mortality rate of $20 \%,{ }^{1}$ the risks are real.

ARROWg'ard Blue" "** is your best defense against infection,

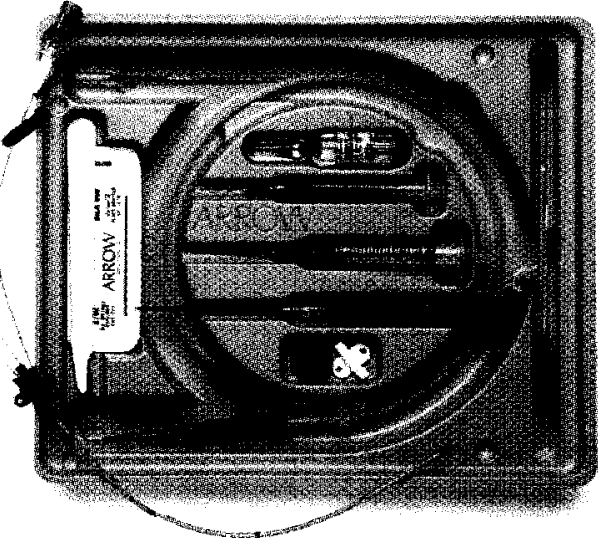

CVC catheters with the built-in protection of ARROWgard Blue" " are up to $80 \%$ less likely to develop bacteremia than unprotected catheters! So you can save up to $80 \%$ of your CVC patients from the risk of a catheter-related bloodstream infection. And you can save your hospital from the expense of $\$ 7,000$ per infection.

To learn about all the benefits of ARROWg'tardBlue" "catheters, contact your Arrow representative or call 1800 523-8446.

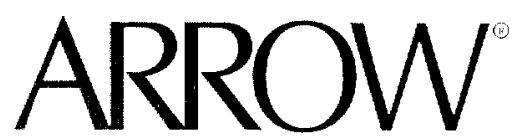

IN TERNATIONAL, INC. 